\title{
PERBANDINGAN STATUS KEBERSIHAN GIGI DAN MULUTPADA ANAK BERKEBUTUHAN KHUSUS SLB-B DAN SLB-C KOTA TOMOHON
}

\author{
${ }^{1}$ Vivie Indahwati \\ ${ }^{2}$ Max F. J. Mantik \\ ${ }^{3}$ Paulina N. Gunawan \\ ${ }^{1}$ Kandidat Skripsi Program Studi Pendidikan Dokter Gigi Fakultas Kedokteran \\ ${ }^{2}$ Bagian Ilmu Kesehatan Anak Fakultas Kedokteran \\ ${ }^{3}$ Program Studi Pendidikan Dokter Gigi Fakultas Kedokteran \\ Universitas Sam Ratulangi Manado \\ Email: vivieindahwati@yahoo.com
}

\begin{abstract}
Special need children is children with disability mental, physical, and emotion which different with the normal children, thus their more needed parents help in keeping hygene especially oral hygene. Every disability they have influenced the behaviour of special need children in keeping their oral hygiene. This study aimed to obtain the difference of oral hygiene between special needs children in SLB-B and SLB-C in Tomohon.This was a descriptive analytical study. Samples were obtained by total sampling method. This study was conducted at SLB-B GMIM Damai Tomohon and SLB-C Katolik Santa Anna Tomohon. There were 101 children in this study. The results of independent $t$ test showed that there were significant differences between the mean value of OHI-S status at SLB-B (1.86) and the mean value OHI-S status at SLB-B ( 2.50) with a $\mathrm{P}$ value of $<0,05$. Conclusion: Oral hygiene of SLB-B children was significantly better than of SLB-C children.
\end{abstract}

Keywords: oral hygiene, special need children

\begin{abstract}
Abstrak: Anak berkebutuhan khusus merupakan anak yang memiliki keterbatasan mental, fisik dan emosi yang berbeda dengan anak normal, sehingga mereka memerlukan bantuan dalam menjaga kebersihan diri khusunya kebersihan gigi dan mulut. Perbedaan keterbatasan yang mereka miliki, memengaruhi perilaku anak berkebutuhan khusus dalam menjaga kebersihan gigi dan mulut. Penelitian ini bertujuan untuk melihat bagaimana perbedaan status kebersihan gigi dan mulut pada anak berkebutuhan khusus di SLB-B dan SLB-C kota Tomohon, Jenis penelitian yang digunakan adalah deskriptif analitik. Pengambilan sampel penelitian ini secara total sampling. Pengambilan data dilaksanakan di SLB-B GMIM Damai Tomohon dan SLB-C Katolik Santa Anna Tomohon. Jumlah anak dalam penelitian sebanyak 101 anak. Hasil penelitian diolah dengan uji statistik $t$ tidak berpasangan (independent $t$ test).Dari uji statistik diperoleh bahwa terdapat perbedaan rerata yang bermakna, antara status OHI-S SLB-B dengan nilai rata-rata 1,86 dibandingkan status OHI-S SLB-C dengan nilai rata-rata 2,50 dan nilai $\mathrm{p}<0,05$. Simpulan: Rerata status kebersihan gigi dan mulut SLB-B lebih baik secara bermakna dibandingkan dengan SLB-C.
\end{abstract}

Kata kunci: kebersihan gigi dan mulut, anak berkebutuhan khusus

Kebersihan gigi dan mulut merupakan hal yang sangat penting. Beberapa masalah gigi dan mulut bisa terjadi karena kurangnya menjaga kebersihan gigi dan mulut misalnya karies atau lubang pada gigi, karies dapat mengenai siapa saja tanpa 
mengenal usia. Anak merupakan usia rentan terhadap karies dan penyakit mulut lainnya karena masih memerlukan bantuan dari orang tua maupun keluarga untuk membimbing dalam menjaga kebersihan gigi dan mulutnya begitu pula pada anak berkebutuhan khusus yang memiliki resiko yang sangat tinggi pada masalah kebersihan gigi dan mulutnya karena memiliki keterbatasan dalam dirinya.

Anak berkebutuhan khusus merupakan anak yang memiliki keterbatasan mental, fisik dan emosi yang berbeda dengan anak normal. Anak berkebutuhan khusus mengalami gangguan dalam berkembang, baik dari segi fisik maupun mentalnya serta memerlukan pelayanan yang spesifik. Berbeda dengan anak pada umumnya, mereka mengalami hambatan dalam belajar dan perkembangan baik permanen maupun temporer yang disebabkan oleh faktor lingkungan, faktor dalam diri anak sendiri, atau kombinasi keduanya.

Sesuai dengan UU RI No.23 Tahun 2003 tentang Perlindungan Anak, yang disebut Anak yaitu "Seseorang yang belum berusia 18 tahun (delapan belas) tahun, termasuk anak yang masih dalam kandungan" perlindungan anak adalah segala kegiatan untuk menjamin dan melindungi anak dan hak-haknya agar dapat hidup, tumbuh, berkembang dan berpartisipasi secara optimal sesuai dengan harkat dan martabat kemanusiaan, serta mendapat perlindungan dari kekerasan dan diskriminasi, termasuk anak yang menyandang Autisme. ${ }^{1}$

Pendidikan yang diterima di SLB dibuat agar anak berkebutuhan khusus ini dapat beraktivitas sehari hari dengan baik walaupun dibatasi dengan kekurangnya. Misalnya dalam hal menjaga kebersihan gigi dan mulutnya. Anak berkebutuhan khusus tentunya diberikan pendidikan agar dapat melakukan aktivitas yang memelihara kesehatan fisiknya.

Beberapa penelitian telah dilakukan pada anak berkebutuhan khusus tentang gambaran kebersihan gigi dan mulut pada anak cacat di SLB YPAC Manado dengan hasil persentase kebersihan gigi dan mulut baik 9 anak (29,03), sedang 18 anak $(58,07)$ dan buruk 4 anak $(12,90)$ dengan mengambil jenis kecacatan pada anak tunadaksa 4 orang, tunagrahita 17 orang, dan tunarungu 10 orang. $^{2}$

Berdasarkan penelitian tersebut peneliti tertarik untuk melihat perbandingan status kebersihan gigi dan mulut pada anak berkebutuhan khusus yang bersekolah di sekolah khusus jenis kelainanya di SLB yang berada di kota Tomohon yaitu SLB-B GMIM Damai Tomohon dan SLB-C Katolik Santa. Anna Tomohon. Menurut survei awal, kedua SLB ini merupakan satu-satunya SLB khusus Tunarungu dan Tunagrahita yang berada di Tomohon dan belum pernah dilakukan penelitian.

\section{METODE PENELITIAN}

Penelitian ini menggunakan jenis penelitian deskriptif analitik. Penelitian ini dilaksanakan pada tanggal 5-12 Juni 2015. Populasi pada penelitian ini seluruh anak berkebutuhan khusus yaitu berjumlah 121 yang terdaftar di SLB-B GMIM Damai Tomohon berjumlah 71 anak berusia 6-24 tahun dan SLB-C Katolik Santa Anna Tomohon berjumlah 50 anak, berusia 1026 tahun.

Metode pengambilan sampel yang digunakan metode total samplingyaitu suatu pengambilan sampel yang dilakukan dengan cara memakai seluruh populasi dalam pelaksanaan penelitian yang berjumlah 101anak yang sesuai kriteria inklusi. Variabel penelitian ini yaitu status kebersihan gigi dan mulut dan anak berkebutuhan khusus. Instrumen penelitian yang digunakan pada penelitian ini yatu alat pemeriksaan status kebersihan gigi dan mulut (OHI-S)dan biodata siswa.

Pengukuran status kebersihan gigi dan mulut dengan menggunakan suatu Indeks OHI-S dengan menjumlahkan skor debris dan kalkulus dengan cara melibatkan 6 gigi yang diperiksa yaitu gigi 16, 11, 26, 31, 36, 46 kemudian hasil dari pemeriksaan dicatat 
pada lembar formulir Pemeriksaan OHI-S.

Data yang digunakan dalam penelitian ini dianalisis dengan menggunakan uji $t$ tidak berpasangan (Independent $t$ test) digunakan untuk mengetahui dan menganalisis perbandingan status kebersihan gigi dan mulut pada anak berkebutuhan khusus di SLB-B dan SLBCdata diperoleh $\mathrm{p}<0,05$ yang berarti terdapat perbedaan rerata yang bermakna antara dua kelompok data dan disajikan dalam bentuk tabel kemudian dideskripsikan berdasarkan distribusi frekuensi dan hasil analisis data.

\section{HASIL PENELITIAN}

Penelitian dilaksanakan di kota Tomohon yang terdapat dua sekolah luar biasa khusus tunarungu (SLB-B) dan khusus tunagrahita (SLB-C). Jumlah anak dalam penelitian ini yaitu berjumlah 101 anak, dari 61 anak SLB-B dan anak SLB-C.

Tabel 1. Distribusi frekuensi karakteristik anak berdasarkan jenis kelamin di SLB-B GMIM Damai Tomohon

\begin{tabular}{ccc}
\hline $\begin{array}{c}\text { Jenis } \\
\text { Kelamin }\end{array}$ & Frekuensi & (\%) \\
\hline laki-laki & 18 & 45 \\
Perempuan & 22 & 55 \\
\hline Total & 40 & 100 \\
\hline
\end{tabular}

Tabel 2. Distribusi frekuensi karakteristik anak berdasarkan jenis kelamin di SLB-C Katolik Santa Anna Tomohon

\begin{tabular}{ccc}
\hline Jenis Kelamin & Frekuensi & $(\%)$ \\
\hline laki-laki & 26 & 42,6 \\
Perempuan & 35 & 57,4 \\
Total & 61 & 100 \\
\hline
\end{tabular}

Tabel 3. Distribusi frekuensi karakteristik anak berdasarkan umur di SLB-B GMIM Damai Tomohon dan SLB-C Katolik Santa Anna Tomohon

\begin{tabular}{ccccc}
\hline \multirow{2}{*}{ Umur (Tahun) } & \multicolumn{2}{c}{$\begin{array}{c}\text { SLB-C Katolik Santa Anna } \\
\text { Tomohon }\end{array}$} & \multicolumn{2}{c}{$\begin{array}{c}\text { SLB-B GMIM Damai } \\
\text { Tomohon }\end{array}$} \\
& Frekuensi & $\%$ & Frekuensi & $\%$ \\
\hline 10 & 3 & 7,5 & 10 & 16,4 \\
11 & 5 & 12,5 & 2 & 3,3 \\
12 & 6 & 15 & 1 & 1,6 \\
13 & 4 & 10 & 3 & 4,9 \\
14 & 3 & 7,5 & 6 & 9,8 \\
15 & 3 & 7,5 & 4 & 6,6 \\
16 & 3 & 7,5 & 8 & 13,1 \\
17 & 5 & 12,5 & 4 & 6,6 \\
18 & 3 & 7,5 & 10 & 16,4 \\
19 & 2 & 5 & 4 & 6,6 \\
20 & 0 & 0 & 4 & 6,6 \\
21 & 1 & 2,5 & 0 & 0 \\
22 & 1 & 2,5 & 3 & 4,9 \\
23 & 1 & 2,5 & 0 & 0 \\
24 & 0 & 0 & 2 & 3,3 \\
Total & 40 & 100 & 61 & 100 \\
\hline
\end{tabular}


Indahwati, Mantik, Gunawan: Perbandingan status kebersihan...

Tabel 4. Distribusi frekuensi Status kebersihan gigi dan mulut di SLB-B GMIMDamai Tomohon

\begin{tabular}{ccc}
\hline Kategori OHI-S & Frekuensi & $\%$ \\
\hline BAIK & 22 & 36,1 \\
SEDANG & 39 & 63,9 \\
BURUK & 0 & 0,0 \\
Total & 61 & 100 \\
\hline
\end{tabular}

Tabel 5. Distribusi frekuensi Status kebersihangigi dan mulut di SLB-C Katolik Santa AnnaTomohon

\begin{tabular}{ccc}
\hline Kategori OHI-S & Frekuensi & $\%$ \\
\hline BAIK & 6 & 15 \\
SEDANG & 21 & 52,5 \\
BURUK & 13 & 32,5 \\
Total & 40 & 100 \\
\hline
\end{tabular}

Tabel 6. Hasil analisis perbedaan rerata status kebersihan gigi dan mulut di SLB-B dan SLB-C kota Tomohon.

\begin{tabular}{cccc}
\hline Status OHI-S & N & Rerata \pm SD & $p$ \\
\hline SLB-B & 61 & $1,86 \pm 0,75$ & 0,000 \\
SLB-C & 40 & $2,50 \pm 0,98$ & \\
\hline
\end{tabular}

\section{BAHASAN}

Penelitian ini bertujuan untuk mengetahui perbandingan status kebersihan gigi dan mulut pada anak berkebutuhan khusus SLB-B dan SLB-C kota Tomohon. Pada penelitan ini anak berjumlah 101anak, dari 61 anak SLB-B dan 40 anak SLB-C. Pada Tabel 1 menunjukkan distribusi frekuensi karakteristik anak berdasarkan jenis kelamin di SLB-B yang terdiri dari laki-laki 26 anak (42,6\%) dan perempuan 35 anak (57,4\%) sedangkan Tabel 2 menunjukkan distribusi frekuensi karakteristik anak berdasarkan jenis kelamin di SLB-C yang terdiri dari lakilaki 18 anak (45\%) dan perempuan 22 anak (55\%) dengan demikian di SLB-B dan SLB-C memiliki jumlah anak perempuan lebih banyak dibandingkan dengan anak laki-laki.

Tabel 3 menunjukkan distribusi frekuensi karakteristik anak berdasarkan umur anak yang aktif mengikuti kegiatan belajar sampai bulan juni 2015 di SLB-B dan SLB-C, diperoleh umur paling banyak di SLB-B pada anak berumur 12 tahun berjumlah 6 anak dan umur paling sedikit pada anak umur 21, 22, 23 tahun dengan rata-rata berjumlah satu anak. sedangkan di SLB-C diperoleh umur paling banyak pada anak berumur 10 tahun dan 18 tahun dan umur paling sedikit pada anak umur 12 tahun berjumlah satu anak.

Pada Tabel 4 Menunjukkan status kebersihan gigi dan mulut anak di SLB-B. Tabel tersebut dapat dilihat bahwa pada anak tunarungukebersihan gigi dan mulutnya tergolong baik diperoleh 22 anak (36,1\%) termasuk kategori baik, dan tergolong sedang 39 anak (63,9\%). Hal ini serupa dengan penelitian yang dilakukan Putra di Manado padatahun 2011 diperoleh hasil penelitian bahwaanak tunarungu mempunyai kebersihan gigi dan mulut baik dan sedang hal ini dikarenakan kesehatan fisik yang hampir sama dengan anak normal lainnya tidak menghambat anak tunarungu dalam menjaga kebersihan gigi 
dan mulutnya meskipun memilki keterbatasan dalam mendengar dan berkomunikasi. $^{2}$

Pada Tabel 5 menunjukkan status kebersihan gigi dan mulut anak di SLB-C. Tabel tersebut dapat dilihat bahwa pada anak tunagrahita kebersihan gigi dan mulutnya tergolong sedang sebanyak 22 anak (53,5\%). Tergolong baik sebanyak enam anak (15\%) dan buruk sebanyak 13 anak (32,5\%). Menurut Hardiani hal ini dipengaruhi oleh beberapa faktor yaitu faktor perilaku anak, kemampuan anak dalam melayani diri yang kurang, frekuensi menyikat gigi yang jarang dan kurangnya pelayanan kesehatan gigi dan mulut pada anak tunagrahita sehingga mengakibatkan kebersihan gigi dan mulut kurang terpelihara dengan baik. ${ }^{2,3}$

Berdasarkan prosedur penelitian tersebut, pada Tabel 6 denganmenggunakan uji statistik $\mathrm{t}$ tidak berpasangan (independent $t$ test) diperoleh bahwa terdapat perbedaan rerata yang bermakna antara status OHI-S SLB-B dan status OHIS SLB-C. Terdapat selisih perbedaan rerata sebesar 0,64 antara status OHI-S SLB-B dan SLB-C karena nilai $\mathrm{p}<0,05$ maka diambil kesimpulan rerata status kebersihan gigi dan mulut SLB-B lebih baik secara bermakna dibandingkan dengan SLB-C. Hal ini dikarenakan karena anak berkebutuhan khusus memiliki keterbatasan dalam dirinya, pada anak tunagrahita yang memiliki cara berpikir sederhana, daya tangkap dan daya ingat yang lemah, dengan pengertian bahasa dan berhitung juga sangat lemah, dengan daya tangkap yang lemah membuat orang tua lebih sulit mengajarkan sikat gigi pada anak tunagrahita karena lebih membutuhkan pengulangan dan perhatian khusus sehingga kemampuan anak dalam menyikat gigi dengan baik dan benar sangat kurang dan daya ingat yang lemah pada anak tunagrahita membuat anak tunagrahita sering lupa dalam menyikat gigi.

Dibandingkan dengan anak tunarungu memiliki keterbatasan dalam mendengar yang mengakibatkan kurangnya informasi yang didapatkan, termasuk informasi tentang kebersihan gigi dan mulut akan tetapi memiliki daya tangkap dan daya ingat hampir sama dengan anak normal sehingga anak tunarungu masih dapat menjaga kebersihan gigi dan mulutnya sendiri. $^{3-6}$

\section{SIMPULAN}

Berdasarkan hasil penelitian yang dilakukan di SLB-B GMIM Damai Tomohon dan SLB-C Katolik Santa Anna Tomohon, dapat disimpulkan:

1. Terdapat perbedaan yang bermakna antara status kebersihan gigi dan mulut pada anak berkebutuhan khusus di SLB-B GMIM Damai Tomohon dan SLB-C Katolik Santa Anna Tomohon..

2. Kebersihan gigi dan mulut pada anak berkebutuhan khusus di SLB-B GMIM Damai Tomohon tergolong sedang dan SLB-C Katolik Santa Anna Tomohon tergolong buruk.

\section{SARAN}

1. Pelayanan kesehatan untuk anak berkebutuhan khusus perlu dilaksanakan melalui sistem pelayanan kesehatan yang ada seperti UKGS (Unit Kesehatan Gigi Sekolah), puskesmas, dan pelayanan kesehatan lainnya. Pemeriksaan rutin kesehatan disekolah dilakukan sesuai dengan keterbatasan yang anak miliki sehingga dapat diperoleh hasil yang efektif.

2. Perlu diberikan penyuluhan tentang kesehatan gigi dan mulut serta cara pemeliharaan kebersihan gigi dan mulut yang baik bagi anak berkebutuhan khusus, guru, serta orang tua. Pada saat guru, maupun dokter dari pihak sekolah memberikan penyuluhan akan lebih baik jika disertai praktek langsung oleh masing-masing anak dan dilakukan secara berulang-ulang, sehingga anak akan lebih mengingat dan dapat melakukannya sendiri.

3. Untuk anak tunagrahita (retardasi 
mental atau keterbelakangan mental) dapat dibantu oleh orang tua/wali atau guru dalam melakukannya. Disinilah orang tua sangat berperan penting untuk dapat terus membantu, mengawasi, maupun memberikan motivasi bagi anak dalam upaya menjaga kebersihan gigi dan mulutnya. Anak tunagrahita juga memerlukan penanganan terpadu dari berbagai disiplin ilmu, baik kedokteran, pendidikan khusus, psikologi, psikiatri, keperawatan maupun komunikasi. Untuk itu perlu adanya penelitian lebih lanjut dari berbagai disiplin ilmu tersebut, dan dapat dilakukan penelitian yang melihat status kebersihan gigi dan mulut pada anak tunagrahita yang menggunakan sikat gigi elektrik dan sikat gigi biasa. Sedangkan untuk anak tunarungu memerlukan layanan khusus yaitu layanan bina bicara dan layanan bina presepsi bunyi dan irama.

\section{UCAPAN TERIMA KASIH}

Ucapan terima kasih disampaikan pada Prof. Dr. dr. Adrian Umboh,Sp.A (K) dan drg. Michael A. Leman, M.MedEd serta semua pihak yang baik secara langsung maupun tidak langsung telah menumbuhkan ide atau gagasan dalam pemikiran penulis.

\section{DAFTAR PUSTAKA}

1. Mulyadi K. Sutadi R. Autism is Curible. Jakarta: PT. Elex Media Komputindo; 2014. h. 1-3.

2. Putra N, Kandou J, Leman MA. Gambaran kebersihan gigi dan mulut pada anak cacat di SLB YPAC Manado. 2011. h. 31.

3. Hardiani KA, Kiswaluyo, Hadnyanawati H. Hubungan pola asuh orang tua dengan kebersihan rongga mulut anak retardasi mental di SLB-C Yayasan Taman Pendidikan dan Asuhan Jember. Artikel Ilmiah Hasil Penelitian Mahasiswa 2012. h. 1-6.

4. Hanun AN. Komunikasi antarpribadi tunagrahita. Jurnal Penelitian Komunikasi ; 2013. 16(2): 140-141.

5. Soetjiningsih. Tumbuh kembang anak. Jakarta: EGC; 1995. h. 192.

6. Widasari D. Perbedaan status kesehatan gigi dan mulut pada anak tunarungu dengan anak tidak tunarungu usia 6 sampai 12 tahun. [Serial Online] 2010 [Diakses April 2015] Tersedia dalam URL:

http://www.repository.unej.ac.id/hand le/123456789/22177.html. 